\title{
Response: Commentary: Metacognition and Perspective-Taking in Alzheimer's Disease: A Mini-Review
}

\author{
Elodie Bertrand ${ }^{1,2 *}$, Anna Fischer ${ }^{1}$ and Daniel C. Mograbi ${ }^{1,3}$ \\ ${ }^{1}$ Department of Psychology, Pontifical Catholic University of Rio de Janeiro, Rio de Janeiro, Brazil, ${ }^{2}$ Department of \\ Psychology, Universidade Do Grande Rio (Unigranrio), Duque de Caxias, Brazil, ${ }^{3}$ Department of Psychology, Institute of \\ Psychiatry, Psychology \& Neuroscience, King's College London, London, United Kingdom
}

Keywords: metacognition, self-awareness, anosognosia, dementia, Alzheimer's disease

\section{A Commentary on}

Commentary: Metacognition and Perspective-Taking in Alzheimer's Disease: A Mini-Review by Morese, R., Mario, S., and Palermo, S. (2018). Front. Psychol. 9:2010. doi: $10.3389 /$ fpsyg.2018.02010

\section{INTRODUCTION}

\section{OPEN ACCESS}

Edited by:

Rosalba Morese,

University of Italian

Switzerland, Switzerland

Reviewed by:

Sunil Swami,

Cigna, United States

Ricardo de Oliveira-Souza,

D'Or Institute for Research and

Education (IDOR), Brazi

*Correspondence:

Elodie Bertrand

elodie.bertrand1@gmail.com

Specialty section:

This article was submitted to

Cognitive Science,

a section of the journal

Frontiers in Psychology

Received: 29 November 2019 Accepted: 26 February 2020

Published: 24 March 2020

Citation: Bertrand E, Fischer $A$ and Mograbi DC (2020) Response: Commentary: Metacognition and Perspective-Taking in Alzheimer's Disease: A Mini-Review.

Front. Psychol. 11:453

doi: 10.3389/fpsyg.2020.00453
Impaired self-awareness is a frequent characteristic of dementia, particularly Alzheimer's disease (AD; Morris and Mograbi, 2013), leading to various negative consequences for the patients and their caregivers, such as reduced treatment adherence and higher caregiver burden (Seltzer et al., 1997; Patel and Prince, 2001; Bertrand et al., 2013). Lack of self-awareness is a complex phenomenon and its clinical presentation is heterogeneous (Clare et al., 2005). For example, it has been shown that people with AD (PwAD) may present impaired self-awareness for some deficits, but preserved awareness of other difficulties (Vasterling et al., 1995; Verhülsdonk et al., 2013; Bertrand et al., 2019). The Cognitive Awareness Model (CAM; Agnew and Morris, 1998; Morris and Hannesdottir, 2004; Hannesdottir and Morris, 2007; Morris and Mograbi, 2013) provides a neurocognitive explanation of lack of self-awareness, trying to account for the complexity of this concept.

Based on the framework developed by Stuss and Anderson (2004) to understand the structure of consciousness, Morese et al. (2018) pointed to the differences between the notions of anosognosia and self-awareness. The authors explain that awareness follows a hierarchical organization in which anosognosia is related to lower levels and self-awareness to higher levels. Whilst we agree that self-awareness and anosognosia can be distinguished (Mograbi and Morris, 2018), our view about the relationship between these concepts differs in relation to that proposed by Morese and colleagues.

The term impaired self-awareness has been employed in the seminal work of Prigatano to describe how awareness about self-ability, personal characteristics, and self-performance can be impaired in clinical populations (Prigatano, 2005). We believe that self-awareness refers to, as the term implies, awareness processes that take the self as an object (Morin, 2006), and it can be understood in even broader terms than those suggested by Prigatano, potentially also involving processes linked to knowledge about internal states (interoception), body ownership (proprioception, agency), identity (autobiographical memory), and monitoring/regulatory processes (metacognition, emotional regulation).

Anosognosia refers to awareness of having a condition (and, by extension, its symptoms and consequences; Mograbi and Morris, 2018), not necessarily being linked to lower-order processes. 
In fact, it is likely that awareness about having a condition is influenced by higher-order factors such as culture (Mograbi et al., 2012, 2015), illness representations (Mograbi et al., 2012) and premorbid personality (Gilleen et al., 2012). It is possible that impairments in different self-awareness processes may lead to anosognosia (or loss of insight, as employed in the psychiatric literature) in clinical conditions. For example, impaired autobiographical memory may be linked to anosognosia in AD (Mograbi et al., 2009), whilst alterations in sense of agency may explain loss of insight in psychosis (Lysaker and Lysaker, 2010). As indicated above, metacognition can be seen as a self-awareness process, and its impairments may lead to specific forms of anosognosia.

\section{CAM AND EXECUTIVE ANOSOGNOSIA}

Empirical evidence has highlighted an association between frontal lobe dysfunction and reduced self-awareness in $\mathrm{AD}$, both in studies using neuroimaging (Rosen et al., 2010; Zamboni et al., 2013) and studies employing neuropsychological tests of executive functions (Perrotin et al., 2008; Shaked et al., 2014). These data support the idea of a form of anosognosia linked to executive processes (executive anosognosia; Morris and Mograbi, 2013). In the CAM model, comparator mechanisms are responsible for monitoring of performance, comparing the actual performance with previous information about ability stored in a personal data base. The result of this comparison is passed to the metacognitive awareness system, leading to accurate self-awareness. So PwAD might present reduced selfawareness because the comparator mechanisms fail to detect the mismatches between the expected and the current experience. In other words, executive anosognosia, as proposed in the CAM, highlights the association between metacognition and anosognosia, with a deficit in metacognitive abilities leading to anosognosia.

\section{APATHY AND ERROR MONITORING}

Error monitoring is a prerequisite to develop awareness of performance. There is an association between error awareness and apathy in $\mathrm{AD}$, with higher levels of the latter being related to poorer awareness in people with mild $\mathrm{AD}$ and MCI (Jacus, 2017). It is possible that this relationship reflects the importance of emotional processing in error monitoring (Mograbi and Morris, 2014). Emotional reactions mark instances of failed task performance with a level of personal significance, and the absence or diminution of error signals caused by apathy could thus be a leading cause of anosognosia in patients with

\section{REFERENCES}

Agnew, S. K., and Morris, R. G. (1998). The heterogeneity of anosognosia for memory impairment in alzheimer's disease: a review of the literature and a proposed model. Aging Ment. Health 2, 7-19. doi: 10.1080/136078698 56876 neurodegenerative diseases, by preventing them to consider these events when evaluating their abilities (Rosen, 2011). In addition, apathy and anosognosia rely on shared neural networks. The anterior cingulate cortex (ACC) is a possible neural correlate of both phenomena, since it has been shown that cortical gray matter atrophy in the bilateral ACC is related to apathy severity in PwAD (Marshall et al., 2006, 2007). Furthermore, this region is the most likely generator of error related potentials like the error related negativity (ERN; Van Veen and Carter, 2002). Errorrelated activity has also been shown in limbic structures (Polli et al., 2009; Pourtois et al., 2010), suggesting that the amygdala may register motivational significance of motor actions, and the dorsal ACC could provide signals related to failure of cognitive control and behavioral adjustment (Pourtois et al., 2010).

\section{CONCLUSION}

In summary, apparently similar presentations of anosognosia, unawareness of having a condition and its consequences, can be linked to different impairments in self-awareness. For example, difficulties in metacognition may prevent detecting mismatches between expected and current performance, or impaired emotional processing may deprive errors of their affective signature, leading to limited awareness about performance and condition. This is precisely the notion described in the CAM, which tries to deal with heterogeneity of anosognosia in clinical groups, suggesting factors such as memory, executive functions, and top-down/bottom-up modulatory processes that can cause different forms of anosognosia. Future research should explore which self-awareness processes are particularly relevant in the context of specific conditions, investigating the relationship between different self-awareness components and how these relate to awareness of condition, considering the impact of the latter in clinical management of patients.

\section{AUTHOR CONTRIBUTIONS}

All authors listed have made a substantial, direct and intellectual contribution to the work, and approved it for publication.

\section{ACKNOWLEDGMENTS}

DM acknowledges funding from the National Research Council (CNPq ref 312370) and the Carlos Chagas Filho Research Support Foundation (FAPERJ ref 226501). AF receives financial support from the Capes Foundation, Ministry of Education of Brazil. 
Clare, L., Marková, I., Verhey, F., and Kenny, G. (2005). Awareness in dementia: a review of assessment methods and measures. Aging Ment. Health 9, 394-413. doi: 10.1080/13607860500142903

Gilleen, J., Greenwood, K., Archer, N., Lovestone, S., and David, A. S. (2012). The role of premorbid personality and cognitive factors in awareness of illness, memory, and behavioural functioning in Alzheimer's disease. Cogn. Neuropsychiatry 17, 227-245. doi: 10.1080/13546805.2011. 588007

Hannesdottir, K., and Morris, R. G. (2007). Primary and secondary anosognosia for memory impairment in patients with Alzheimer's disease. Cortex 43, 1020-1030. doi: 10.1016/S0010-9452(08)70698-1

Jacus, J.-P. (2017). Awareness, apathy, and depression in Alzheimer's disease and mild cognitive impairment. Brain Behav. 7:e00661. doi: 10.1002/brb3.661

Lysaker, P. H., and Lysaker, J. T. (2010). Schizophrenia and alterations in selfexperience: a comparison of 6 perspectives. Schizophr. Bull. 36, 331-340. doi: $10.1093 /$ schbul/sbn077

Marshall, G. A., Fairbanks, L. A., Tekin, S., Vinters, H. V., and Cummings, J. L. (2006). Neuropathologic correlates of apathy in Alzheimer's disease. Dement. Geriatr. Cogn. Disord. 21, 144-147. doi: 10.1159/000090674

Marshall, G. A., Monserratt, L., Harwood, D., Mandelkern, M., Cummings, J. L., and Sultzer, D. L. (2007). Positron emission tomography metabolic correlates of apathy in Alzheimer disease. Arch. Neurol. 64, 1015-1020. doi: 10.1001/archneur.64.7.1015

Mograbi, D. C., Brown, R. G., and Morris, R. G. (2009). Anosognosia in Alzheimer's disease - The petrified self. Conscious. Cogn. 18, 989-1003. doi: 10.1016/j.concog.2009.07.005

Mograbi, D. C., Ferri, C. P., Sosa, A. L., Stewart, R., Laks, J., Brown, R., et al. (2012). Unawareness of Memory impairment in dementia: a population-based study. Int. Psychogeriatr. 24, 931-939. doi: 10.1017/S1041610211002730

Mograbi, D. C., Ferri, C. P., Stewart, R., Sosa, A. L., Brown, R. G., Laks, J., et al. (2015). Neuropsychological and behavioral disturbance correlates of unawareness of memory impairment in dementia: a population-based study. J. Geriatr. Psychiatry Neurol. 28, 3-11. doi: 10.1177/0891988714541868

Mograbi, D. C., and Morris, R. G. (2014). On the relation among mood, apathy, and anosognosia in Alzheimer's disease. J. Int. Neuropsychol. Soc. 20, 2-7. doi: $10.1017 /$ S1355617713001276

Mograbi, D. C., and Morris, R. G. (2018). Anosognosia. Cortex 103, 385-386. doi: 10.1016/j.cortex.2018.04.001

Morese, R., Mario, S., and Palermo, S. (2018). Commentary : metacognition and perspective-taking in Alzheimer's disease : a mini-review. Front. Psychol. 9:2010. doi: 10.3389/fpsyg.2018.02010

Morin, A. (2006). Levels of consciousness and self-awareness: a comparison and integration of various neurocognitive views. Conscious. Cogn. 15, 358-371. doi: 10.1016/j.concog.2005.09.006

Morris, R. G., and Hannesdottir, K. (2004). "Loss of 'Awareness' in Alzheimer's Disease,"in The Cognitive Neuropsychology of Alzheimer's Disease, eds R. G. Morris and J. T. Becker (Oxford: Oxford University Press), 275-296.

Morris, R. G., and Mograbi, D. C. (2013). Anosognosia, autobiographical memory and self knowledge in Alzheimer's disease. Cortex 49, 1553-1565. doi: 10.1016/j.cortex.2012.09.006

Patel, V., and Prince, M. (2001). Ageing and Mental health in a developing country: who cares? Qualitative studies from Goa, India. Psychol. Med. 31, 29-38. doi: 10.1017/S0033291799003098

Perrotin, A., Tournelle, L., and Isingrini, M. (2008). Executive functioning and memory as potential mediators of the episodic feeling-of-knowing accuracy. Brain Cogn. 67, 76-87. doi: 10.1016/j.bandc.2007.11.006
Polli, F. E., Wright, C. I., Milad, M. R., and Dickerson, B. C. (2009). Hemispheric differences in amygdala contributions to response monitoring. Neuroreport 20, 398-402. doi: 10.1097/WNR.0b013e328324edb8

Pourtois, G., Vocat, R., N’Diaye, K., Spinelli, L., Seeck, M., and Vuilleumier, P. (2010). Errors recruit both cognitive and emotional monitoring systems: simultaneous intracranial recordings in the dorsal anterior cingulate gyrus and amygdala combined with FMRI. Neuropsychologia 48, 1144-1159. doi: 10.1016/j.neuropsychologia.2009. 12.020

Prigatano, G. P. (2005). Disturbances of self-awareness and rehabilitation of patients with traumatic brain injury: a 20-year perspective. J. Head Trauma Rehabil. 20, 19-29. doi: 10.1097/00001199-20050100000004

Rosen, H. J. (2011). Anosognosia in neurodegenerative disease. Neurocase 17, 231-241. doi: 10.1080/13554794.2010.522588

Rosen, H. J., Alcantar, O., Rothlind, J., Sturm, V., Kramer, J. H., Weiner, M., et al. (2010). Neuroanatomical correlates of cognitive self-appraisal in neurodegenerative disease. Neuroimage 49, 3358-3364. doi: 10.1016/j.neuroimage.2009. 11.041

Seltzer, B., Vasterling, J. J., Yoder, J. A., and Thompson, K. A. (1997). Awareness of deficit in Alzheimer's disease: relation to caregiver burden. Gerontologist 37, 20-24. doi: 10.1093/geront/37.1.20

Shaked, D., Farrell, M., Huey, E., Metcalfe, J., Cines, S., Karlawish, J., et al. (2014). Cognitive correlates of metamemory in Alzheimer's disease. Neuropsychology 28, 695-705. doi: 10.1037/neu00 00078

Stuss, D. T., and Anderson, V. (2004). The frontal lobes and theory of mind: developmental concepts from adult focal lesion research. Brain Cogn. 55, 69-83. doi: 10.1016/S0278-2626(03)00271-9

Van Veen, V., and Carter, C. S. (2002). The anterior cingulate as a conflict monitor: FMRI and ERP studies. Physiol. Behav. 77, 477-482. doi: 10.1016/S0031-9384(02)00930-7

Vasterling, J. J., Seltzer, B., Foss, J. W., and Vanderbrook, V. (1995). Unawareness of deficit in Alzheimer's disease: domain-specific differences and disease correlates. Neuropsychiatry Neuropsychol. Behav. Neurol. 8, 26-32.

Verhülsdonk, S., Quack, R., Höft, B., Lange-Asschenfeldt, C., and Supprian, T. (2013). Anosognosia and depression in patients with Alzheimer's Dementia. Arch. Gerontol. Geriatr. 57, 282-287. doi: 10.1016/j.archger.2013. 03.012

Zamboni, G., Drazich, E., McCulloch, E., Filippini, N., Mackay, C. E., Jenkinson, M., et al. (2013). Neuroanatomy of impaired self-awareness in Alzheimer's disease and mild cognitive impairment. Cortex 49, 668-678. doi: 10.1016/j.cortex.2012.04.011

Conflict of Interest: The authors declare that the research was conducted in the absence of any commercial or financial relationships that could be construed as a potential conflict of interest.

Copyright (C) 2020 Bertrand, Fischer and Mograbi. This is an open-access article distributed under the terms of the Creative Commons Attribution License (CC BY). The use, distribution or reproduction in other forums is permitted, provided the original author(s) and the copyright owner(s) are credited and that the original publication in this journal is cited, in accordance with accepted academic practice. No use, distribution or reproduction is permitted which does not comply with these terms. 